\title{
Application of Sealing Construction Technology for Precast Concrete City Pipe Gallery Interface
}

\author{
Feng Dan, Cheng Yuanpeng, Li Yang, Han Shaojie, Zhang Siqing \\ Hebei University of Architectur, University, Hebei, China
}

Keywords: Comprehensive Pipe Gallery Project; precast; waterproof technology; sealing

\begin{abstract}
Interface seal is the most important quality index of precast concrete culverts. The interface of prefabricated concrete square culvert is an important factor to form the quality of comprehensive pipeline gallery. The following points should be guaranteed: (1) the reliability of the sealing of the interface during the whole life of the pipeline; (2) the connection mode of prefabricated concrete square culvert should adapt to the requirements of construction technology and be simple and convenient; (3) the connection of prefabricated concrete square culvert should be convenient. In production and manufacture; (4) the connection mode of precast concrete culverts is simple and low cost. Therefore, the selection of appropriate interface treatment measures plays an important role in the later quality of underground comprehensive pipeline gallery. As a result, there are more structural joints, so strengthening the waterproof work is a very important content. Therefore, combined with the practice of a project, the application of waterproofing technology is analyzed.
\end{abstract}

\section{Introduction}

Urban underground comprehensive pipeline Gallery Project (hereinafter referred to as pipeline Gallery project), mainly in the construction of underground tunnel space, the relevant power, communications, heating, gas and water supply and drainage engineering management for an organic collection, to achieve its unified design planning and scientific construction management. To promote efficient urban operation is an important infrastructure and lifeline. In order to effectively avoid the problem of road zipper, avoid the cobweb density over the city, so as to better manage the functions of urban infrastructure, which plays an indispensable role in the construction of a harmonious urban ecological environment. But waterproofing in pipe gallery works is the core work, so the application of waterproof technology must be strengthened.

\section{Urban Integrated Corridor}

\subsection{Basic Situation}

The pipeline Gallery project belongs to the main municipal engineering project of A city. The length of the whole construction line is $12.19 \mathrm{~km}$. It is laid in underground form, with a total of 12 stations. The average distance between each station is $1.11 \mathrm{~km}$. Closely combined with the characteristics of the pipeline Gallery project, pay attention to waterproofing construction of its main structure and detail joints. The waterproofing system adopted by the pipeline Gallery Project has strong complexities, so as to better meet the later use of the project and ensure the safe and efficient operation of the whole pipeline Gallery project.

\subsection{Waterproof Scheme}

The pipeline Gallery Project is the comprehensive carrier of the whole underground pipeline. Its main function is to carry municipal pipelines. Therefore, the pipeline Gallery project strictly meets the design requirements. The basic waterproof grade is 2 , but the waterproof grade of weak current cable and high voltage cable is 1 . Because the engineering site belongs to soft soil geological conditions, it is easy to occur deformation and soil corrosion in the foundation. Therefore, in the 
waterproofing design of underground structures in this project, we always adhere to the basic principles of prevention, rigidity and flexibility, multiple lines of defense, local conditions, scientific and comprehensive management to carry out waterproofing design work. In the concrete waterproofing design, the main points of waterproofing design are as follows: First, P-type coil is used to pre-lay the large surface of the platform floor, the thickness of which is $1.5 \mathrm{~mm}$, while non-woven fabric of $200 \mathrm{~g}$ per square meter and non-curable rubber asphalt waterproofing coating of $2 \mathrm{~mm}$ thickness are used to construct the composite waterproofing system in its section. In addition, the non curing rubber asphalt waterproof coating is added at the point, with the thickness of $2.5 \mathrm{~mm}$. The other is to design the deformation joint with a distance of $30 \mathrm{~m}$, and to set up many pipeline entrances and exits in the cable and pipeline locations in the gallery. Because it belongs to the weak part, it adopts the method of combining the external sealing belt with the steel plate sealing belt to double waterproof, and carries on the sealant treatment in the detail. The three is to protect the outer wall of the pipe wall by polyethylene foam section, and the thickness of the protective plate is $10 \mathrm{~mm}$. On the basis of doing a good job in waterproof design, we should do well in selecting waterproof materials. Waterproofing performance is directly related to the durability of the structure, so in the process of underground engineering fortification, the key points of fortification should be determined according to its use function, life and environmental factors. And the choice of waterproof material is the key to ensure the quality of its fortification. Therefore, we always pay attention to the selection of waterproof materials in this pipe gallery project. Specifically, the permeability coefficient of reinforced concrete is relatively small because of its porous and multi-phase, but the corrosion and destruction of reinforcing steel caused by groundwater. In order to meet the service life of the pipe gallery structure design (100 years), when selecting waterproof materials, the non-curable waterproof coating and sealant are finally used.

In the construction of this pipeline gallery, its waterproofing construction process is as follows: 1 ) strengthening the treatment of the base; 2) practically doing a good job in the construction of waterproofing strengthening layer; 3) scraping non-curing coatings on the surface; 4) inspecting the thickness of coatings; 5) checking and accepting the quality of the project; and 5) construction of protective coatings [1].

\section{Pipe Gallery Interface Sealing Construction Technology}

\subsection{Main Points of Waterproof Technology for This Pipe Gallery Project}

When the construction machinery and materials are ready, side walls and roofs are repeatedly compacted to ensure their surface smoothness. On this basis, timely removal of uneven surface and honeycomb gap of the grass-roots to ensure that the grass-roots treatment is clean, to ensure that the grass-roots level and solid, strictly prohibit the existence of seepage and floating slurry. On the basis of dealing with the grass-roots units, we need to do well in the construction of waterproof layer. In the construction of waterproof layer, non-curable rubber asphalt waterproof coating is applied mainly through wall pipes, catchment pits, deformation joints, construction joints and post-pouring belts. The thickness of the strengthening layer is $2.5 \mathrm{~mm}$ and the width is more than $500 \mathrm{~mm}$. On this basis, the waterproof layer is laid. In the pre-laying process of the base plate coil, the elastic line is located mainly on the plain concrete cushion of grade C20, the first pre-laid coil is spread according to the datum line, and the second coil is laid, and the isolation film of the overlapping part is measured to overlap the coil after uncovering. In the process of coil pre-laying, it is strictly forbidden to stretch, and ensure that it is aligned with the baseline to prevent deviation. On the basis of doing the above work, we need to carry out the construction of waterproof layer in time. In this pipe gallery project, the main layer is to lay a layer of polyester nonwoven isolation layer, while the side wall is laid with polyethylene foam board protection layer. The thickness should be between $6 \mathrm{~mm}$ and $10 \mathrm{~mm}$, and the top layer is protected by the fine concrete protection layer. The thickness of the protective layer is $70 \mathrm{~mm}$ in the pipe gallery project, which is finally effective. The construction quality control of foot waterproofing layer needs [2]. 


\subsection{Node Waterproof Construction Technology of Pipe Gallery Project}

In the pipe gallery project, the waterproof construction of yin yang angle is a very important content. In the waterproofing construction of Yinyang angle, the following construction techniques should be mastered: first, in the Yinyang angle of the bottom plate, the main way is to wrap the coil, while in the Yinyang angle of the side wall, roof and facade, it is necessary to use paint for waterproofing. The two is to use the cement mortar to strengthen the chamfering of the corner. The three is to make the fillet of more than $10 \mathrm{~mm}$ in Yang angle. In the pipe gallery project, the waterproof construction of pile head is a very important content. In waterproofing construction of pile head, the following construction techniques should be mastered: first, before construction of waterproofing layer of pile head, loose floating soil and concrete should be removed in time, and cement-based crystalline permeable waterproofing coating should be applied twice on pile head, the amount of brushing per square meter should be $2 \mathrm{~kg}$. Secondly, the shade corner of pile head and waterproof layer should adopt one-component polyurethane, because it will expand and seal the end after encountering water, so as to ensure that its waterproof performance is improved. In the waterproofing construction of overturning structure, this project mainly adopts non-solidified coatings and polyester isolating materials to carry out composite waterproofing, while in its exterior, it uses brick walls to protect the waterproofing layer. On this basis, polymer cement mortar is used to strengthen the sealing treatment of the ground and the closure. In waterproofing construction of upright column and wall-piercing pipe fittings, this project mainly uses sealant to chamfer the negative corner of the pipe fittings, while the positive corner is strengthened by non-curing paint. The wall and water stop flanges are fixed by mosaic sealing strips. In the composite waterproof layer, the bonding part between the pipe and the pipe is strengthened by metal hoop. Non-curing coatings and polyester isolating materials are used for composite waterproofing of roof reverse beams, while fine stone concrete protective layer is poured on the top of the reverse beams, and cement mortar is used for plastering construction on both sides of the reverse beams, and brick masonry is used to strengthen the treatment of the reverse beams. In waterproofing construction of construction joints, the following technical points should be grasped earnestly: Firstly, steel plate waterproof Belt should be set in the middle of roof and side wall. Two, when the waterproof reinforcement layer is constructed, the width of each side is $250 \mathrm{~mm}$. Thirdly, in the roof reinforcement layer, the sealant is applied on the fixed point and the side wall is fixed by the external water stop belt.

\section{Conclusion}

In summary, combining with the practice of a pipe gallery project, the main points of waterproof technology are discussed. In practical projects, we should closely combine the actual situation of the project, determine the waterproof technical scheme and grasp the key points of waterproof technology, so as to better consolidate its waterproof effect, ultimately improve its waterproof performance while promoting its performance, and effectively promote the rapid development of the city.

\section{References}

[1] Ding H, Yu J, Duan Y, et al. Waterproofing Construction for Precast Concrete Stand Plates of the Stadium of Lhasa Sports and Cultural Center[J]. China Building Waterproofing, 2015.

[2] Xiao F, Li M. Research on Construction Technology of Precast Concrete External Wall and Waterproofing Technology of Joints[J]. China Building Waterproofing, 2018.

[3] Chen Y, Guo Z, Dong N, et al. Factory Production Technology for Components of the New Precast Concrete Shear Wall Structure[J]. Construction Technology, 2011.

[4] Cao S L. Methods for Seal Design of Interface of Precast Concrete Utility Tunnel[J]. China Concrete \& Cement Products, 2018. 
[5] Lin Y. Discussion for Development Status of Precast Assembly Utility Tunnel and Water Resistance Sealing Performance of Joint[J]. China Concrete \& Cement Products, 2017. 